This item was submitted to Loughborough's Research Repository by the author.

Items in Figshare are protected by copyright, with all rights reserved, unless otherwise indicated.

\title{
Effect of graphene oxide sheet size on the curing kinetics and thermal stability of epoxy resins
}

PLEASE CITE THE PUBLISHED VERSION

http://dx.doi.org/10.1088/2053-1591/3/10/105303

PUBLISHER

(C) IOP Publishing

VERSION

AM (Accepted Manuscript)

LICENCE

CC BY-NC-ND 4.0

\section{REPOSITORY RECORD}

Wang, Xiao, Jie Jin, Mo Song, and Yue Lin. 2017. "Effect of Graphene Oxide Sheet Size on the Curing Kinetics and Thermal Stability of Epoxy Resins”. figshare. https://hdl.handle.net/2134/23971. 


\title{
1 Effect of graphene oxide sheet size on the curing kinetics 2 and thermal stability of epoxy resins
}

\author{
3 Xiao Wang ${ }^{1}$, Jie $\mathrm{Jin}^{2}$, Mo Song ${ }^{2}$ and Yue $\mathrm{Lin}^{3}$ \\ 41 Center of Membrane Technology and Application Engineering, Chongqing Institute of Green and \\ $5 \quad$ Intelligent Technology, Chinese Academy of Sciences, Chongqing 400714, China. \\ 62 Department of Materials, Loughborough University, Loughborough, Leicestershire LE11 3TU, \\ $7 \quad$ UK \\ 83 School of Materials, University of Manchester, Oxford Road, Manchester M13 9PL, UK \\ 9 E-mail: wangxiao@cigit.ac.cn
}

10 Keywords: graphene oxide, epoxy resin, curing kinetics, thermal stability, sheet size

Abstract

13 This work revealed the influences of graphene oxide (GO) sheet size on the curing kinetics and thermal 14 stability of epoxy resins. A series of GO/epoxy nanocomposites were prepared by the incorporation of 15 three different sized GO sheets, namely GO-1, GO-2 and GO-3, the average size of which was $1610.79 \mu \mathrm{m}, 1.72 \mu \mathrm{m}$ and $0.70 \mu \mathrm{m}$, respectively. The morphologies of the nanocomposites were observed 17 by field emission gun scanning electron microscope (FEGSEM). The dispersion quality of each sized 18 GO was comparable in the epoxy matrix. The curing kinetics was investigated by means of differential scanning calorimetry (DSC) and analysed based on kinetics model. Addition of a small amount of GO (0.1 wt\%) exhibited strong catalytic effect on the curing reaction of epoxy resin. The activation energy

21 was reduced by $18.9 \%, 28.8 \%$ and $14.6 \%$ with addition of GO-1, GO-2 and GO-3, respectively. GO-2 with medium size $(1.72 \mu \mathrm{m})$ showed the most effective catalysis on the cure. The thermal stability of the cured resins was evaluated based on thermogravimetric analysis. GO/epoxy nanocomposites showed improved the thermal stability in the range of $420-500{ }^{\circ} \mathrm{C}$, compared with the pure resin. A $\sim 4 \%$ more residue was obtained in each of the incorporated system. The variations of GO sheet size did not influence the enhancement effect on the thermal stability.

\section{Introduction}


Epoxy resins, which possess low cost and health hazard, have been the most important thermosetting resins in industry for various applications. They have been widely used as engineering adhesives, paints, surface coatings, electrical insulations, construction materials and components for automotive, marine and aerospace composites [1]. Recently, reinforcements of epoxy resins by the addition of nanofillers have been intensively reported [2-5]. The epoxy nanocomposites show improved properties with a low filler loading. The nanoparticles are more efficient in enhancing the performances of epoxy resins, compared with traditional particles. It has been demonstrated that the properties of epoxy and its nanocomposites highly depend on the effects of nanofillers on the curing behavior of the matrix [6-9]. They could catalyze the curing process and influence the network formation of the resin. On the contrary, the nanofillers could act as physical hindrance that inhibits the cure of chains. These effects could change the curing kinetics, network formation and structure of the composite, and finally affect its properties. Therefore, in order to develop high performance epoxy nanocomposite, it is essential to understand how the addition of nanofillers influences cuing kinetics.

Epoxy resins are oxirane-containing oligomers that require suitable hardener to participate the reaction of epoxide groups. The cure of epoxy resins shows auto-catalyze behavior caused by the $-\mathrm{OH}$ groups generated during the cure [10]. For a diglycidyl ether of bisphenol-A (DGEBA)/ 4,4'-diaminodiphenylsulfone (DDS) system, in the course of cure, each primary amine of DDS reacts with an epoxy group of DGEBA, via ring opening, and forms a $\mathrm{CH}_{2}-\mathrm{NH}$ bond as well as a pendant hydroxyl group. The hydroxyl group is known to accelerate subsequent ring opening reactions. The resultant secondary amines further react with remaining epoxy rings in a similar manner, by which the polymer chains are crosslinked at a slower rate [11]. Accordingly, the nanofillers with functionalized groups such as hydroxyl could affect the curing behavior of epoxy resins. So far, the influences of various nanofillers have been investigated and reported. Zhang et al. [12] found that the incorporation of POSS- $\mathrm{NH}_{2}$ decreased the reaction rate of epoxy resins at early stages, while this effect was not obvious at the late stages of the curing reaction. The average activation energy of the 
curing reaction of the epoxy nanocomposites was higher than the pristine system. In contrast, the presence of nanosilica was reported to act as catalyst that led to a higher reactivity and decreased the activation energy of epoxy resins [13]. Ferdosian et al. evaluated the catalytic effect of nanoclay on the epoxy resins. The addition of clay reduced the activation energy of the cure reaction [14]. Similar catalytic behavior in the curing process of epoxy nanocomposites was also observed by the incorporation of carbon nanofillers such as CNTs $[15,16]$, carboxylic functionalization of CNTs [17, 18], silica-coated CNTs [19] and carbon black [6]. However, carbon nanofibres (CNFs) [20, 21] or fluorine modified CNTs [22] hardly affected the cure kinetics of epoxy resins. Expanded graphite (EG) did not significantly impede the cure of epoxy [23], and its effect was related to the concentration of EG incorporated [24].

Among the nanoparticles, graphene is a two dimensional materials with high aspect ratio and tremendous surface area. Its advantages in reinforcing epoxy resins over other fillers have been reported $[25,26]$. However, the performances are highly dependent on the size of graphene incorporated. Recent work has revealed that the sheet size of graphene oxide (GO) significantly influences the fracture toughness [25] and the mechanical properties [27] of GO/epoxy nanocomposites. In the investigations of the effect of GO on curing behavior of epoxy resins, Qiu at al. [28] found that the presence of GO slightly decreased the curing temperature of epoxy resins. The oxygen functionalities including hydroxyl and carboxyl groups on the GO catalyzed the curing reaction. Activation energy of the reaction reduced with the increase of GO content, especially in the later stage. However, it conflicts with Ryu [29] and Li's [30] study, where the activation energy increased by the addition of GO in the epoxy resins. The effect of GO on the curing process of epoxy is still in debate. On the other hand, in order to meet the demand for high temperature applications of epoxy resins, it is important to investigate the thermal stability of the epoxy and its nanocomposites with GO. Although a few studies have been done to evaluate their thermal properties [31-33] and the curing behavior, the effects of GO sheet size are not clear. In this study, three different sized GO sheets were used to prepare a series of GO/epoxy nanocomposites. We attempt to reveal 
the effects of GO sheet size on the curing kinetics and thermal stability of epoxy resins. This work essentially contributes to a judicious selection of filler size in the development of epoxy nanocomposites.

\section{Experimental}

\subsection{Materials}

Three sizes of graphite flakes, which were denoted as G-1, G-2 and G-3, were purchased from Qingdao Graphite Company. The average size of the graphite flakes was $150 \mu \mathrm{m}, 7 \mu \mathrm{m}$ and $4 \mu \mathrm{m}$, respectively. Diglycidyl ether of bisphenol-A (DGEBA) epoxy (D.E.R*331) (epoxide equivalent weight is $182-192 \mathrm{~g} \cdot \mathrm{eq}^{-1}$ ) was obtained from Dow Chemical. The 4,4'-diaminodiphenylsulfone (DDS) curing agent was supplied by Sigma-Aldrich. Their structures were presented in figure 1. Acetone was provided by Fisher-Scientific Ltd.
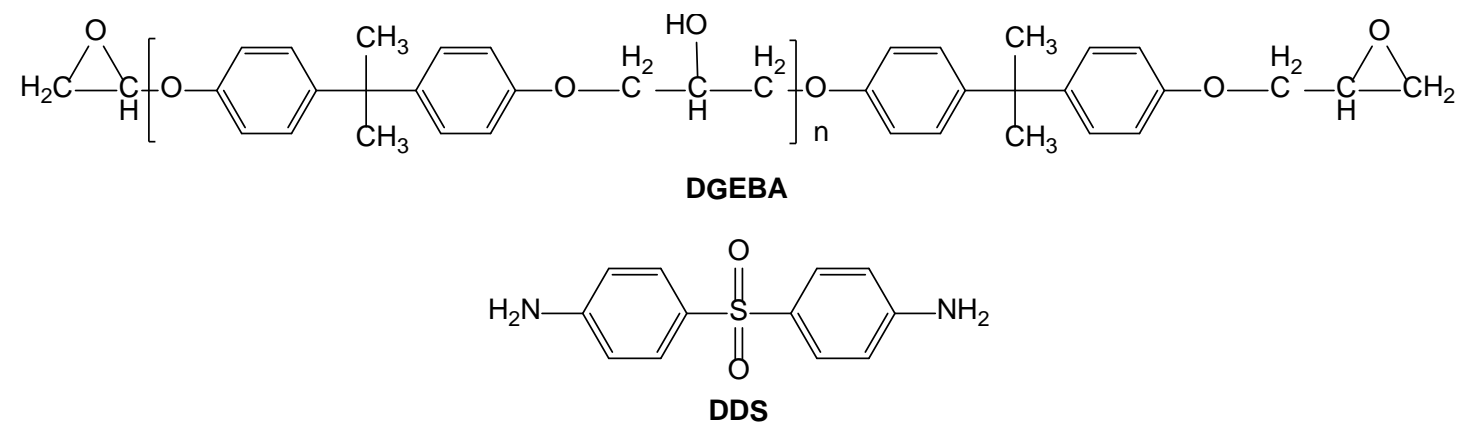

Figure 1. Structures of DGEBA and DDS.

\subsection{Fabrication of GO and GO/epoxy mixture}

GO was fabricated from graphite by using Hummers’ method [34]. The GO was denoted as GO-1, GO-2 and GO-3, respectively. In terms of the preparation of GO/epoxy mixture, the GO was firstly dispersed in acetone at concentration of $1 \mathrm{mg} \mathrm{ml}^{-1}$, by means of ultrasonication for $30 \mathrm{~min}(300 \mathrm{w})$ at room temperature. DGEBA/GO mixtures were then prepared by adding calculated amount of GO (0.1 wt\%) into the DGEBA. The mixture was stirred at $80^{\circ} \mathrm{C}$ for $1 \mathrm{~h}$, followed by degassing in a vacuum oven $(800 \mathrm{mBar})$ for 1 day at $80^{\circ} \mathrm{C}$ to remove the solvent. 
DDS curing agent was added into the DGEBA/GO mixture and stirred at $135^{\circ} \mathrm{C}$ for $1 \mathrm{~h}$. The weight ratio of DDS to DGEBA was 1:4. All the prepared GO/epoxy mixtures were sealed and stored at $-20^{\circ} \mathrm{C}$ for further use.

\subsection{Characterization}

A Shimadzu Fourier Transform Infrared (FTIR) 8400s spectrophotometer was used to record the spectra of the three types of GO in the range of 4000 to $750 \mathrm{~cm}^{-1}$. The resolution is $2 \mathrm{~cm}^{-1}$ over 64 scans. Particle size of GO was determined by using a Malvern Instruments Mastersizer. Layered GO structure was observed by a Philips Tecnai high resolution transmission electron microscopy (HRTEM). The GO was dispersed in acetone, and dropped on copper grid for observation. A TA Instruments Differential Scanning Calorimetry (DSC) calorimeter was used for quasi-isothermal tests, in order to reveal the curing behavior of epoxy and its nanocomposites at $170^{\circ} \mathrm{C}, 175^{\circ} \mathrm{C}$ and $180^{\circ} \mathrm{C}$, respectively. All the tests were run under a modulated-temperature DSC model with modulation amplitude of $0.5{ }^{\circ} \mathrm{C}$ and a period

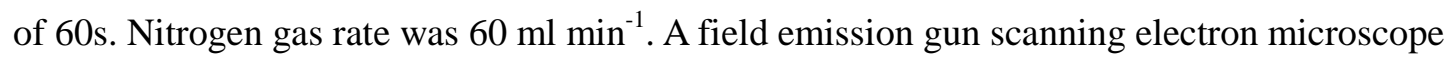
(FEGSEM) LEO 1530VP was used to observe the cross-sectional morphology of the fully cured epoxy and its nanocomposites. The samples were prepared by curing the mixtures at $180^{\circ} \mathrm{C}$ for $1 \mathrm{~h}, 200^{\circ} \mathrm{C}$ for $2 \mathrm{~h}$ and post-cured at $250^{\circ} \mathrm{C}$ for $2 \mathrm{~h}$. Before observation, the cured samples were freeze-fractured in liquid nitrogen and coated with gold by a sputter coater for 60s. The images were taken from area with minimal number of cracks, in order to get good observation of GO dispersion. The thermal stability of the cured epoxy resin and the nanocomposites was revealed by means of thermogravimetric analysis (TGA) on a DSC-TGA 2950 instrument. The samples were heated from $50^{\circ} \mathrm{C}$ to $700{ }^{\circ} \mathrm{C}$ at a rate of $10{ }^{\circ} \mathrm{C} \mathrm{min}{ }^{-1}$. The air rate was $50 \mathrm{ml} \mathrm{min}^{-1}$.

\section{Results and discussion}

Figure 2 shows the FTIR spectra of the three types of GO. They exhibited comparable spectra with the characteristic bands observed at $1250 \mathrm{~cm}^{-1}$ (C-O-C), $1745 \mathrm{~cm}^{-1}(\mathrm{C}=\mathrm{O})$ and $3420 \mathrm{~cm}^{-1}$ 
136 (-OH). It indicates that the three types of GO were functionalized with epoxide, carboxyl and 137 hydroxyl groups, by means of the Hummers’ method. Particle size distribution of the three 138 types of GO was measured and shown in figure 3. Table 1 lists the typical size parameters, 139 including $D_{20}, D_{50}$ and $D_{80}$, which represented the particle size at which $20 \%, 50 \%$ and $80 \%$ 140 of the GO sheets was below this given size. It can be noticed that the GO sheet size decreased 141 from GO-1 to GO-3. In particular, the average size, $D_{50}$, of GO sheets for GO-1, GO-2 and 142 GO-3 was $10.79 \mu \mathrm{m}, 1.72 \mu \mathrm{m}$ and $0.70 \mu \mathrm{m}$, respectively. The edges of the GO sheets were 143 observed by means of HRTEM technique, in order to reveal the layered graphene platelet 144 structure. Based upon a sufficient quantity of observations on the GO sheets, for each type of 145 GO sheets, they were comprised with about 2-5 individual graphene layers. The thickness of 146 the GO sheets was about 1-2 nm. Figure 4 shows the typical images of the edges for GO-1, 147 GO-2 and GO-3. According to the FTIR analysis, size distribution measurement and HRTEM 148 microscopy, the three types of synthesized GO had similar surface chemistry and thickness

149 but differed in surface size. The SEM cross-sectional images of the dispersion morphology for 150 the epoxy and its nanocomposites with the three different sizes of GO were shown in figure 5. 151 It can be observed that the GO sheets were well dispersed in the epoxy matrix. The dispersion 152 quality of each type of GO was comparable. The sizes of the GO sheets were unchanged in 153 the composites. The preparation process did not affect the original sheet size of GO. 


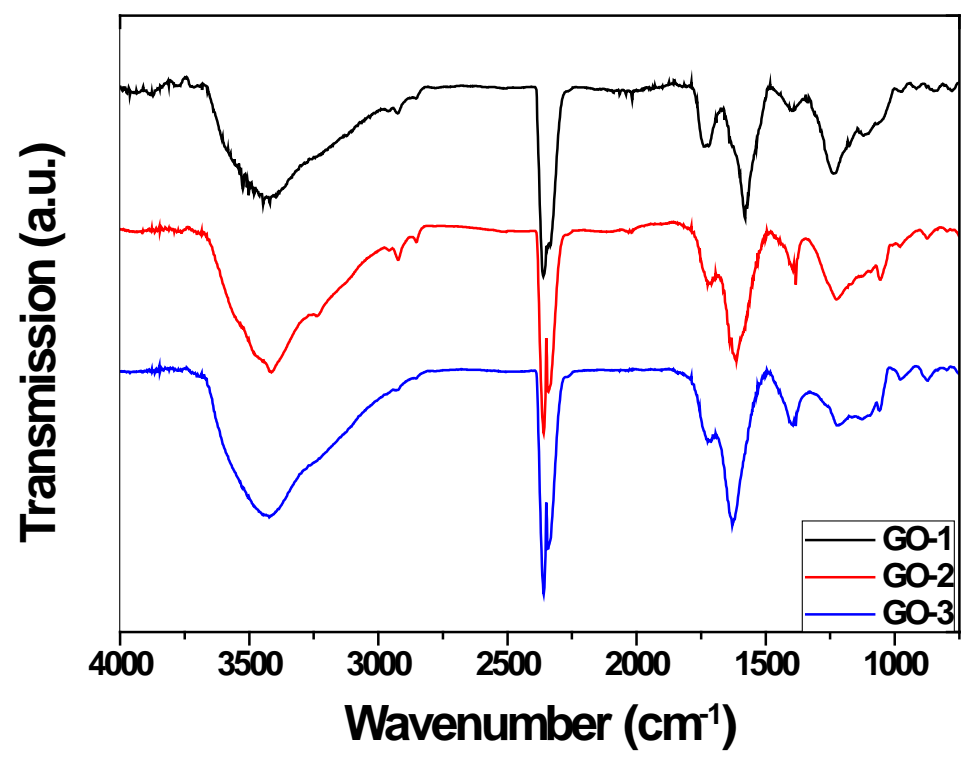

156 Figure 2. FTIR spectra of GO-1, GO-2 and GO-3. The spectra were parallel shifted for 157 clarification.

158

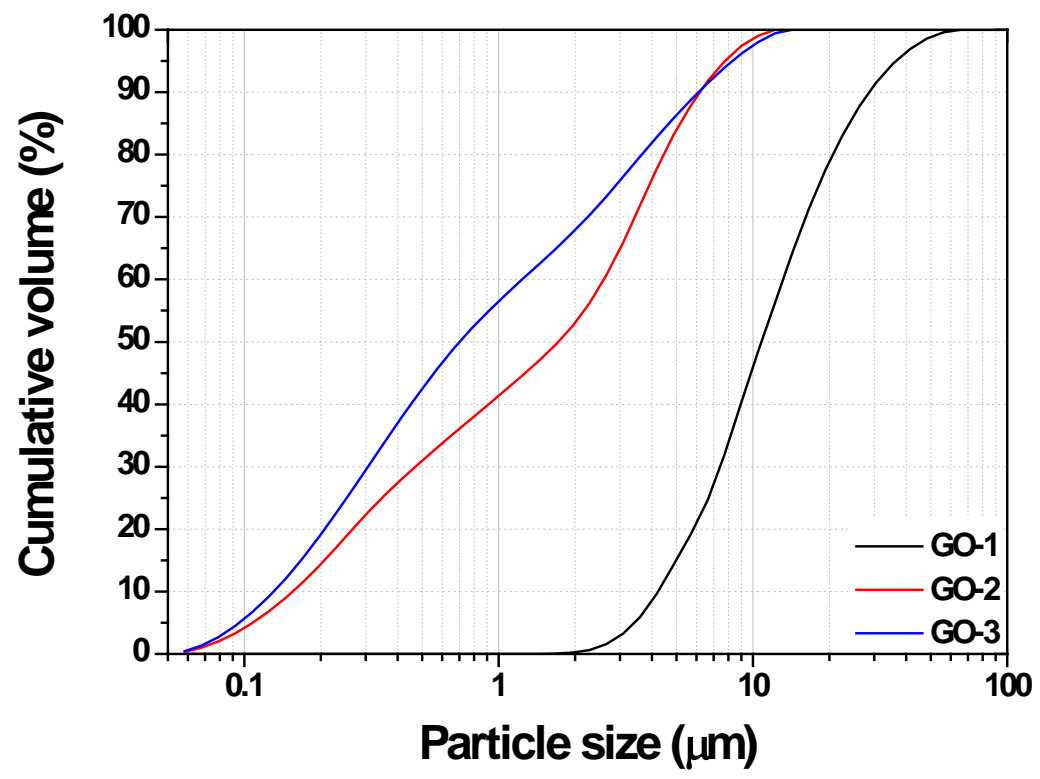

159 Figure 3. Particle size distribution of GO-1, GO-2 and GO-3.

160

161

162

163

164 
Table 1. Key parameters of GO sheet size.

\begin{tabular}{llll}
\hline Type & GO-1 & GO-2 & GO-3 \\
\hline$D_{20}(\mu \mathrm{m})^{\mathrm{a}}$ & 5.82 & 0.27 & 0.21 \\
$D_{50}(\mu \mathrm{m})^{\mathrm{a}}$ & 10.79 & 1.72 & 0.70 \\
$D_{80}(\mu \mathrm{m})^{\mathrm{a}}$ & 20.71 & 4.48 & 3.66 \\
\hline
\end{tabular}
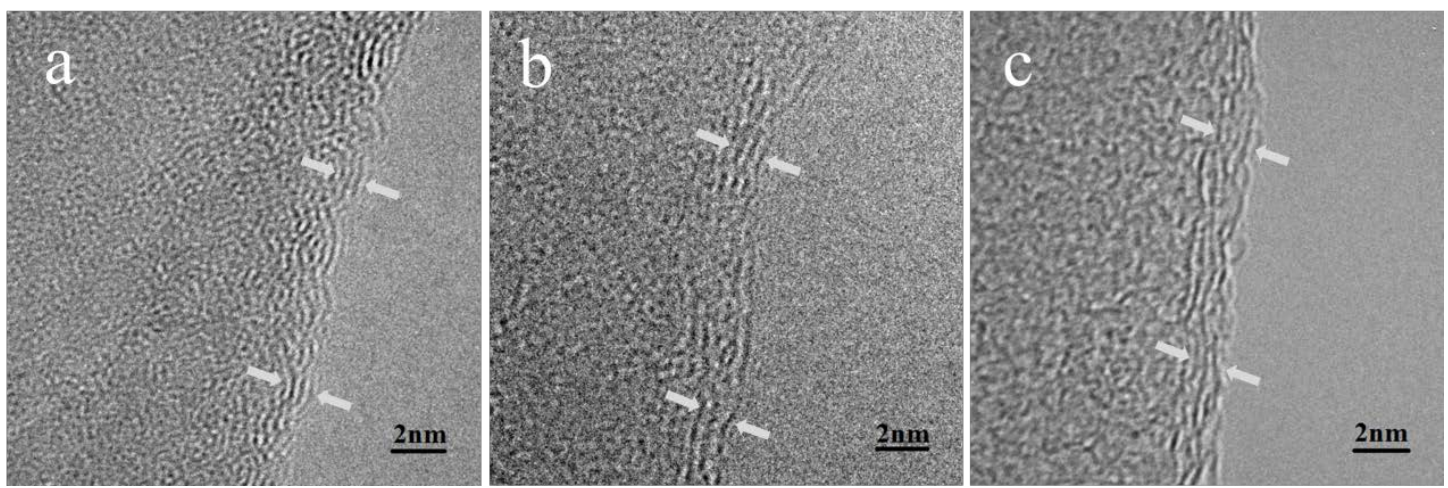

170 Figure 4. HRTEM images of the edges of (a) GO-1, (b) GO-2 and (c) GO-3, showing the layered 171 structure. The thickness of the GO sheets was about 1-2 nm.

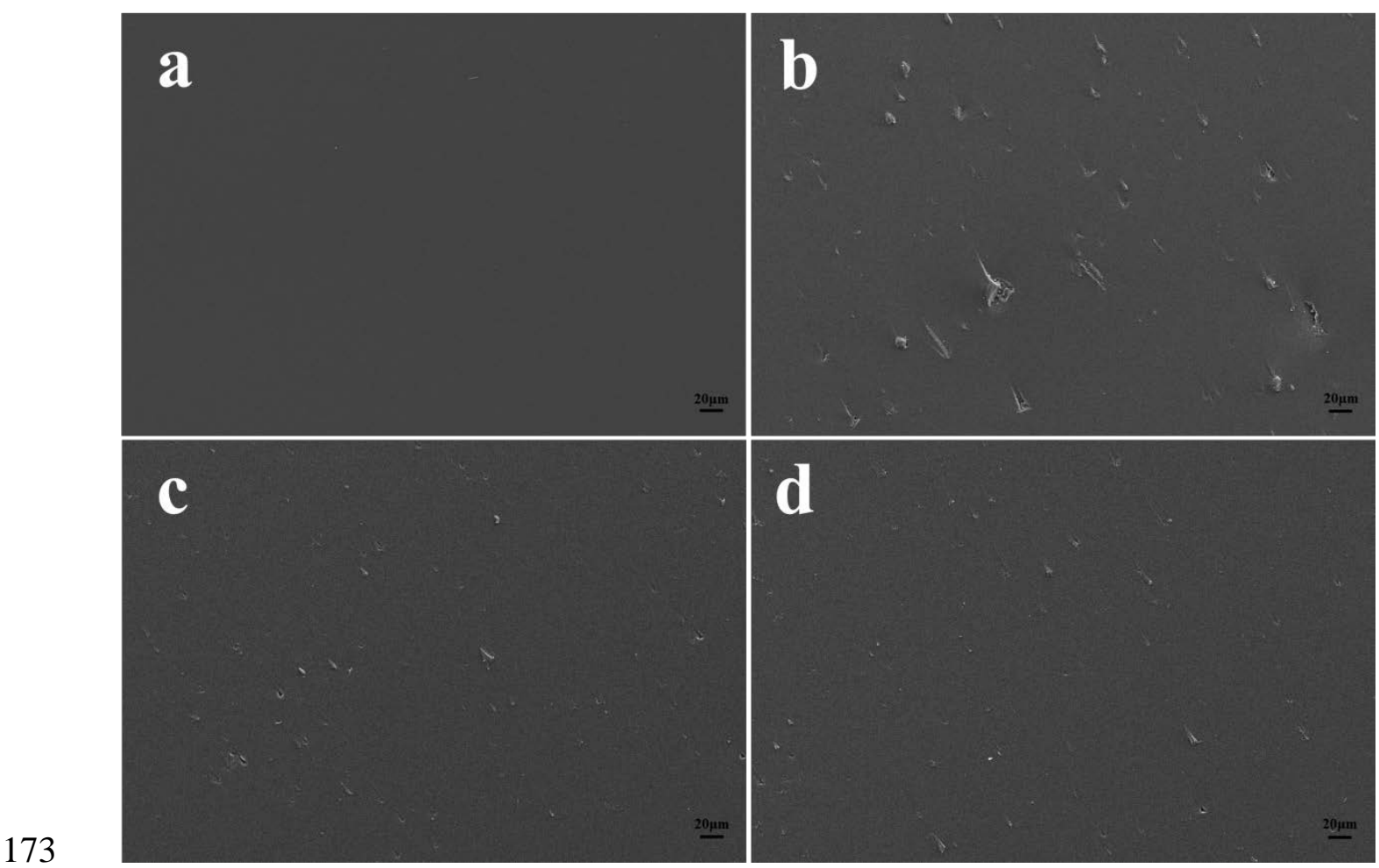

174 Figure 5. SEM cross-sectional images of morphologies for (a) epoxy and its nanocomposites with $1750.1 \mathrm{wt} \%$ (b) GO-1, (c) GO-2 and (d) GO-3. 
178 course including conversion, reaction rate and activation energy. They highly influence the

179 processing ability, network structure and properties of the nanocomposites [32]. The key

180 curing kinetics parameters were assessed by means of quasi-isothermal DSC analysis.

181

182
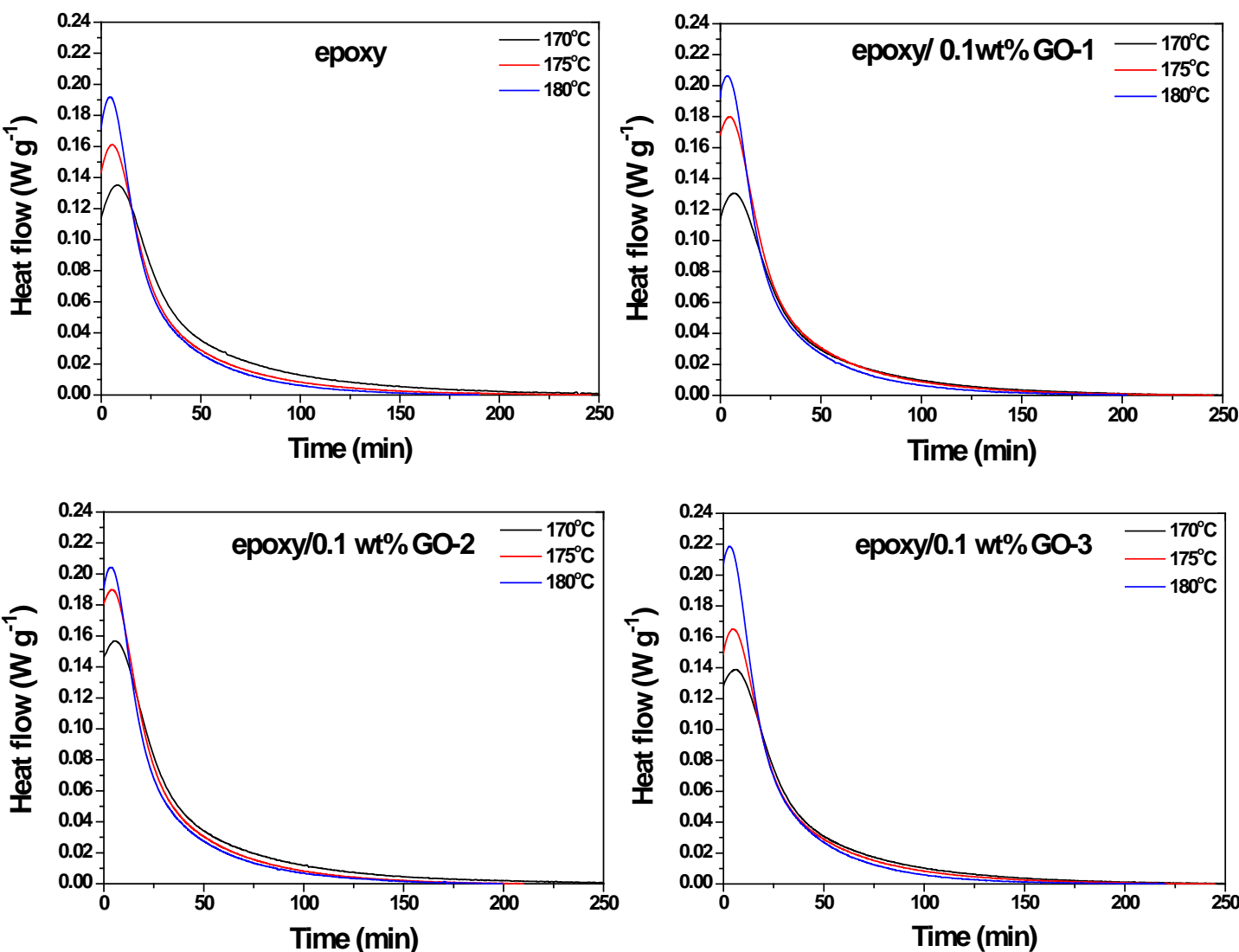

183

184

185

186

187

188

189

190

191

192 

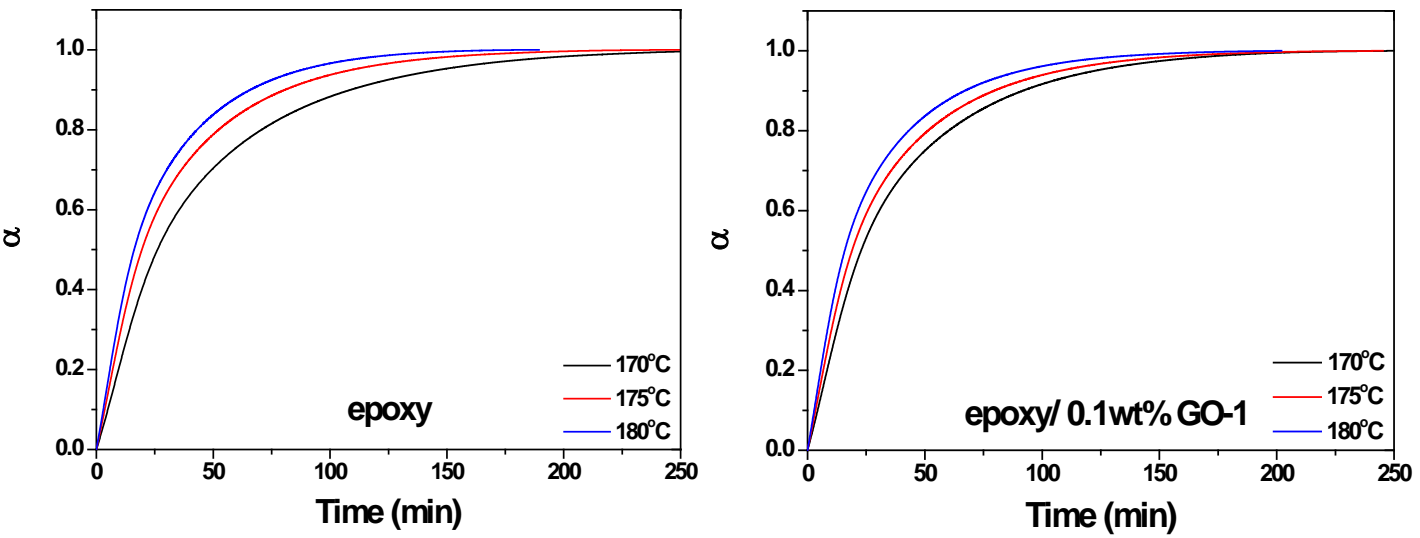

193
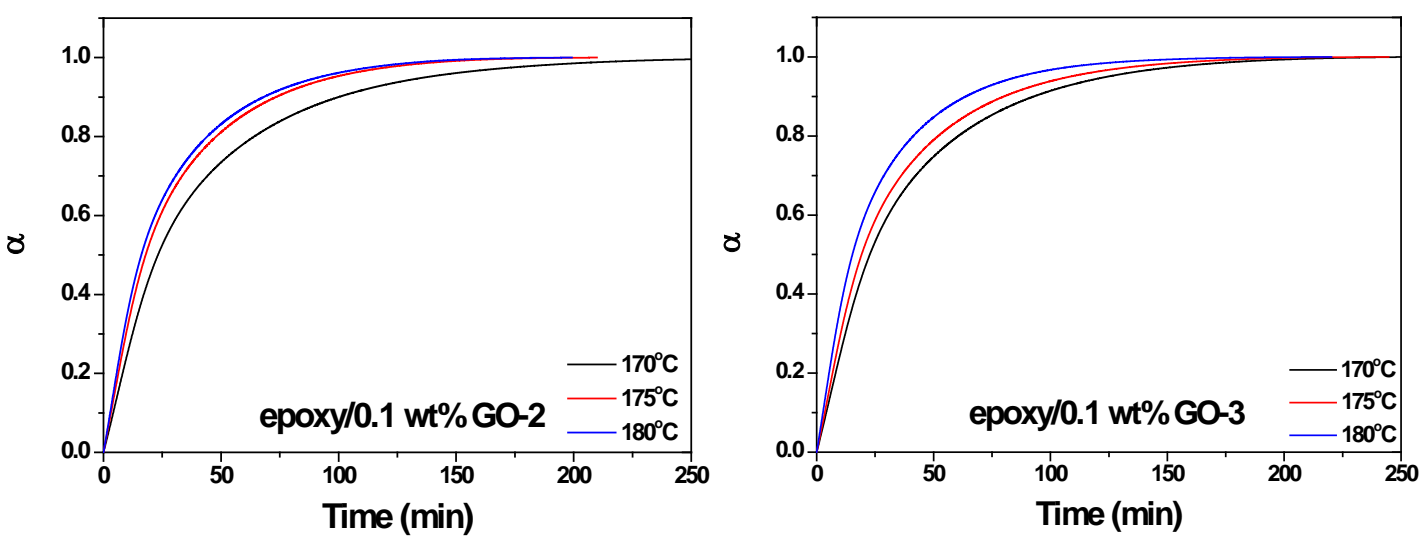

194

195

196

197

198

199

200

201

202

203

204

205

Figure 7. Conversion, $\alpha$, versus curing time for the GO/epoxy nanocomposites at different curing temperatures. 

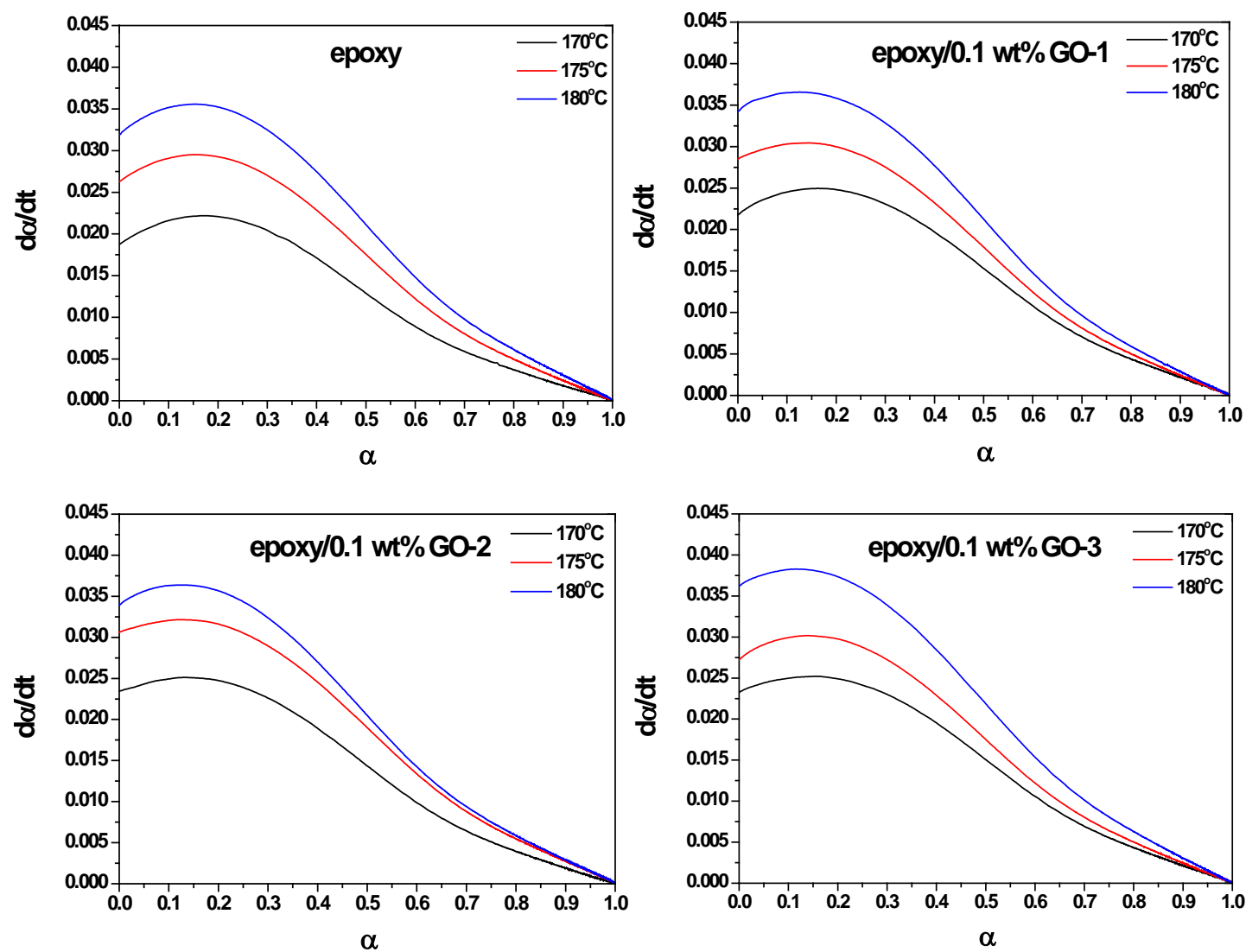

Figure 8. $d \alpha / d t$ versus $\alpha$ for the GO/epoxy nanocomposites at different curing temperatures.

Table 2. Comparison of curing parameters for epoxy and its nanocomposites at different curing temperatures.

\begin{tabular}{llccl}
\hline Temperature $\left({ }^{\circ} \mathrm{C}\right)$ & Epoxy & GO-1/epoxy & GO-2/epoxy & GO-3/epoxy \\
\hline \multicolumn{5}{l}{ Time (min), when maximal heat flow is observed } \\
170 & 8.18 & 6.90 & 5.39 & 6.25 \\
175 & 5.37 & 4.80 & 3.96 & 4.68 \\
180 & 4.47 & 3.52 & 3.50 & 3.08 \\
\hline \multicolumn{5}{c}{} \\
170 & $\alpha^{\prime}$, conversion where maximal $d \alpha / d t$ is observed \\
175 & 0.177 & 0.161 & 0.127 & 0.154 \\
180 & 0.154 & 0.139 & 0.125 & 0.141 \\
\hline
\end{tabular}

213 Figure 6 shows the isothermal DSC plots of heat flow versus curing time for the epoxy

214 resin and its nanocomposites with three types of GO at different curing temperatures. The

215 commencement of curing reaction was accompanied by high value of heat flow, revealing fast

216 initiation process of DGEBA and DDS molecules. Oligomers were subsequently formed and 
217 the chains were built up linearly, where the molecular weight continuously increased.

218 Maximal heat flow was observed a few minutes after the start of reaction. As the curing

219 reaction further proceeded, the polymer chains were crosslinked, followed by the formation of

220 three-dimensional network. The reaction heat flow decreased and finally approached down to

221 zero, suggesting the end of the cure. The GO/epoxy nanocomposites exhibited similar

222 variation of heat flow versus time. However, the maximal heat flow was appeared earlier than

223 pristine epoxy. The corresponding time was referred and listed in table 2 . The presence of GO

224 could accelerate the curing reaction of epoxy resin. Figure 7 shows the plots of conversion, $\alpha$

225 versus time for epoxy and its nanocomposites. $\alpha$ represents the degree of reaction at the

226 particular temperature.

$$
\alpha=\frac{\Delta H_{t}}{\Delta H_{T}}
$$

228 where $\Delta H_{t}$ is the reaction heat from the onset of polymerisation up to time, $t, \Delta H_{T}$ is the total

229 reaction heat at the particular curing temperature. The residual reaction heat was not

230 considered in this study, as it related to the post-cure course. $d \alpha / d t$ is defined as conversion

231 rate at time, $t$.

$$
\frac{d \alpha}{d t}=\frac{1}{\Delta H_{T}} \frac{d \Delta H_{t}}{d t}
$$

The plots of $d \alpha / d t$ versus $\alpha$ are shown in figure 8. It can be observed that during the

234 initiation stage of the curing, the conversion rate of pure epoxy resin increased with the curing process. The reaction intermediates were formed and increased to a sufficient amount, auto-accelerating the reaction. A maximal conversion rate appeared between $\alpha=0.150-0.177$.

237 At higher conversion, the reaction rate decreased owing to the increased viscosity. The trend

238 of the conversion rate was in agreement with auto-acceleration behaviour. With the

239 incorporation of GO, the conversion at the maximal conversion rate (this particular

240 conversion is defined as $\alpha^{\prime}$ ) was shifted to lower value, as demonstrated in table 2. In general, 241 the shift of $\alpha^{\prime}$ reveals a catalytic effect of a filler on cuing reaction [7]. Thus, in this study, the 242 GO could catalyze initial stage of epoxy curing. The catalyzed stage then induced a fast 243 generation of reaction intermediates, followed by an earlier appearance of the maximal 244 conversion rate, compared with pure resin. 
The cure of the GO/epoxy system included several competing reactions. The main mechanism of the catalytic effect of GO on the epoxy curing was illustrated in figure 9. It involved addition and etherification reactions. As presented in figure 9a, Carboxyl (or

248 hydroxyl) group of GO enabled the formation of hydrogen bond with DGEBA, followed by a 249 GO-DGEBA-DDS trimolecular transition complex. The complex was able to accelerate 250 epoxide ring opening. Subsequently, Secondary amine was formed after fast proton transfer.

251 The resultant secondary amine could further react with remaining DGEBA in a similar 252 manner, by the presence of GO catalyst (figure 9b). The epoxide rings were consumed rapidly.

253 When the concentration of unreacted epoxide rings approached to a very low level, GO

254 reacted with the pendant hydroxyl group, creating ether link after dehydration (figure 9c).

a
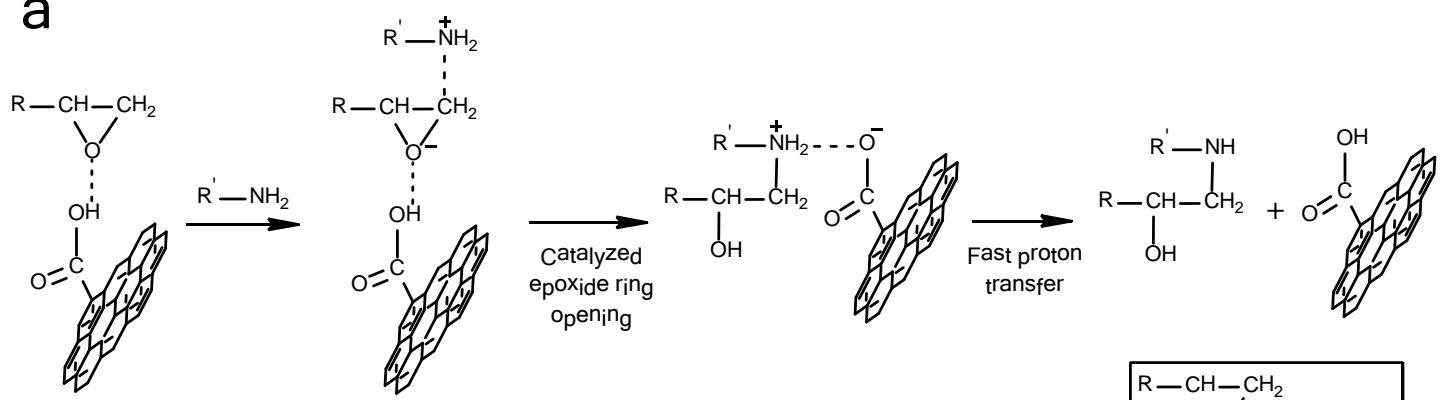

Trimolecular transition state

b
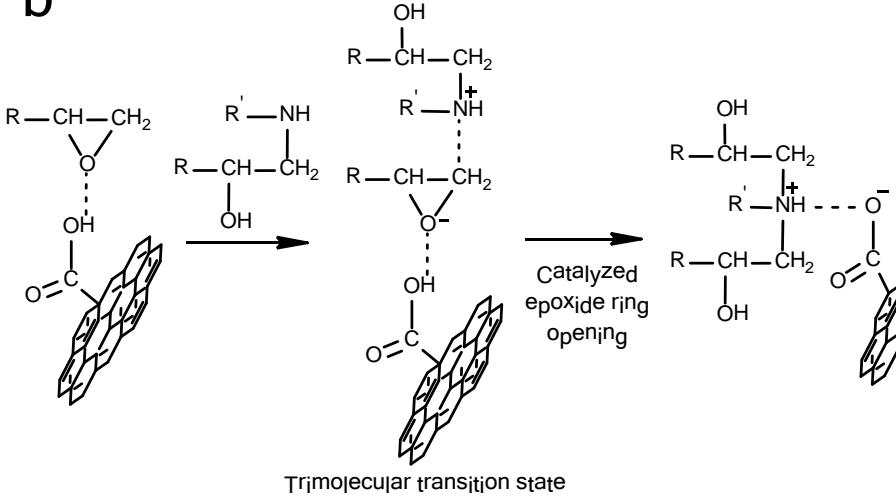

$\begin{array}{cll}\mathrm{R}-\mathrm{CH}-\mathrm{CH}_{2} & \\ / \mathrm{O}^{\prime} & : & \text { DGEBA } \\ \mathrm{R}^{\prime}-\mathrm{NH}_{2} & : & \text { DDS }\end{array}$

C<smiles>[R]C(O)CN([R])CC([R])O</smiles><smiles>Cc1ccccc1C(=O)O</smiles><smiles>[R]C(O)CN([R])CC([R])OC(=O)c1ccccc1</smiles>

Figure 9. Schematic of the catalytic effect of GO on the epoxy curing. (a) GO-catalyzed primary amine addition, (b) GO-catalyzed secondary amine addition, and (c) GO/epoxy etherification. 
Table 3. Curing constants for GO/epoxy nanocomposites.

\begin{tabular}{llllllllll}
\hline Sample & $T\left({ }^{\circ} \mathrm{C}\right)$ & $\begin{array}{l}K_{1}\left(\mathrm{x} 10^{4}\right. \\
\left.\mathrm{s}^{-1}\right)\end{array}$ & $\begin{array}{l}K_{2}\left(\mathrm{x} 10^{4}\right. \\
\left.\mathrm{s}^{-1}\right)\end{array}$ & $m$ & $n$ & $\begin{array}{l}E_{1}(\mathrm{~kJ} \\
\left.\mathrm{mol}^{-1}\right)\end{array}$ & $\begin{array}{l}E_{2}(\mathrm{~kJ} \\
\left.\mathrm{mol}^{-1}\right)\end{array}$ & $\ln A_{1}$ & $\ln A_{2}$ \\
\hline Epoxy & 170 & 2.5 & 5.3 & 0.44 & 1.54 & 94.2 & 55.3 & 17.3 & 7.5 \\
& 175 & 3.6 & 6.5 & 0.46 & 1.51 & & & & \\
& 180 & 4.4 & 7.3 & 0.43 & 1.47 & & & & \\
GO-1/ & 170 & 3.0 & 5.7 & 0.47 & 1.48 & 83.9 & 35.6 & 14.7 & 2.2 \\
Epoxy & 175 & 4.0 & 6.0 & 0.46 & 1.50 & & & & \\
& 180 & 5.0 & 7.0 & 0.47 & 1.51 & & & & \\
GO-2/ & 170 & 3.3 & 5.2 & 0.46 & 1.55 & 59.8 & 37.8 & 8.2 & 2.7 \\
Epoxy & 175 & 4.3 & 5.8 & 0.43 & 1.44 & & & & \\
& 180 & 4.7 & 6.5 & 0.40 & 1.48 & & & & \\
GO-3/ & 170 & 3.2 & 5.0 & 0.45 & 1.47 & 77.2 & 44.2 & 12.9 & 4.4 \\
Epoxy & 175 & 3.8 & 6.0 & 0.42 & 1.49 & & & & \\
& 180 & 5.1 & 6.6 & 0.42 & 1.46 & & & & \\
\hline
\end{tabular}
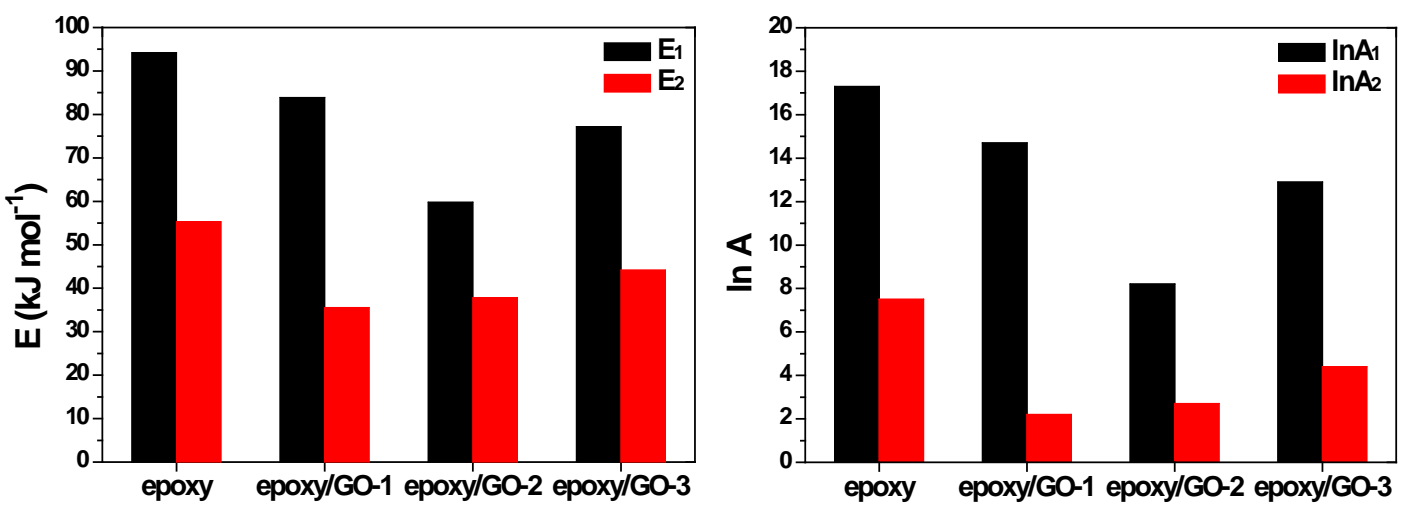

261 Figure 10. Activation energy and pre-exponential factor for epoxy and its nanocomposites.

264 of epoxy resin, activation energy, $E$ was calculated according to Kamal's model [35] on

265 isothermal kinetics analysis. The plots of $d \alpha / d t$ versus $\alpha$ were fitted by the following equation.

$$
\frac{d \alpha}{d t}=\left(K_{1}+K_{2} \alpha^{m}\right)(1-\alpha)^{n}
$$

267 where $K_{1}$ and $K_{2}$ are the reaction rate constants in the initial and autocatalytic stages,

268 respectively. $m$ and $n$ are the reaction order of the cure. Furthermore, the temperature

269 dependent rate constant $K_{i}$ was correlated by the Arrhenius equation.

$$
K_{i}=\operatorname{Aexp}\left(-\frac{E}{R T}\right)
$$


271 where $R$ is the gas constant, $T$ is the absolute temperature and $A$ is the pre-exponential or

272 frequency factor. The curing constants for epoxy resin and its nanocomposites were listed in

273 Table 3. In particular, comparison of $E$ and $\ln A$ between the epoxy with different sizes of GO

274 are shown in figure 10. $E_{1}$ revealed the effect of GO on the epoxy resin at the initial curing

275 stages. In contrast, $E_{2}$ was more important at the later stages, as it showed the influence of GO

276 on the network formation in the epoxy. It can be observed that the presence of GO reduced the

277 activation energy of the reaction, compared with the pure epoxy. The activation energy

278 required for curing was thus declined, which demonstrated the catalytic effect of GO on the

279 cure. Furthermore, the results revealed that $E_{1}$ decreased with the decrease of GO size from

280 GO-1 to GO-2. Meanwhile the $E_{2}$ did not show obvious change. However, with further

281 decreasing the GO size to that of GO-3, both of $E_{1}$ and $E_{2}$ tended to elevate. Similar variations

282 were exhibited in $\ln A_{1}$ and $\ln A_{2}$.

283 Figure 11 shows the plots of activation energy and pre-exponential factor versus

284 conversion, respectively. The onset activation energy of the pure epoxy resin was $94.2 \mathrm{~kJ}$

$285 \mathrm{~mol}^{-1}$. It decreased substantially at the initial stages of the cure, where $0<\alpha<0.2$. The reduced

286 activation energy was benefit to the initiation rate and subsequent auto-acceleration of the

287 cure. Accordingly, the maximal conversion rate appeared at the conversion near 0.2. At the

288 later stages of the reaction after $\alpha=0.2$, the decrease trend of the activation energy became

289 slow. It maintained at a relatively steady level till the end of the cure. The incorporation of the

290 GO reduced the activation energy of the reaction throughout the curing process. Compared

291 with the pure resin, the average activation energy was reduced by $18.9 \%, 28.8 \%$ and $14.6 \%$

292 with addition of GO-1, GO-2 and GO-3, respectively. The GO-2 with medium size showed

293 the biggest reduction on the activation energy, which suggested the optimal catalytic effect on

294 the cure of epoxy resin. It should be noted that although GO induced strong catalytic effect

295 due to its functional groups, the two-dimensional layer structure of graphene could act as

296 space hindrance, which reduced and constrained the mobility of the reactive groups of epoxy.

297 It was adverse to the curing catalysis and efficiency. Since the three sizes of GO had the same

298 surface chemistry, it is believed that the observed difference in the curing behaviour results 
299 from the different hindrance effect from variable GO sizes. In this study, the GO-1 possessed 300 large graphene layer, the size of which was about one order of magnitude bigger than that of 301 GO-2. The presence of GO-1 in the epoxy substantially increased the diffusion distance of the 302 reactive chains surrounding the GO sheets. The hindrance effect from individual graphene 303 layer was significant, compared with that of GO-2. However, as the GO size further reduced 304 to that of GO-3, there was a larger number of GO sheets dispersed in the GO-3/epoxy 305 nanocomposite than other GO-incorporated systems at fixed filler content. The increase in the 306 number of GO sheets induced more hindrance sites than those of GO-1 and GO-2. In addition 307 to the hindrance effect from individual GO sheets, the massive sites could synergistically 308 confine the movement of the reactive chains at a deeper level in larger area. It eventually 309 resulted in higher activation energy. Therefore, GO-2 incorporated nanocomposite showed 310 overall the least hindrance effect throughout the curing reaction. The optimal catalytic effect 311 was obtained by showing the biggest reduction on the activation energy.

313 314 315
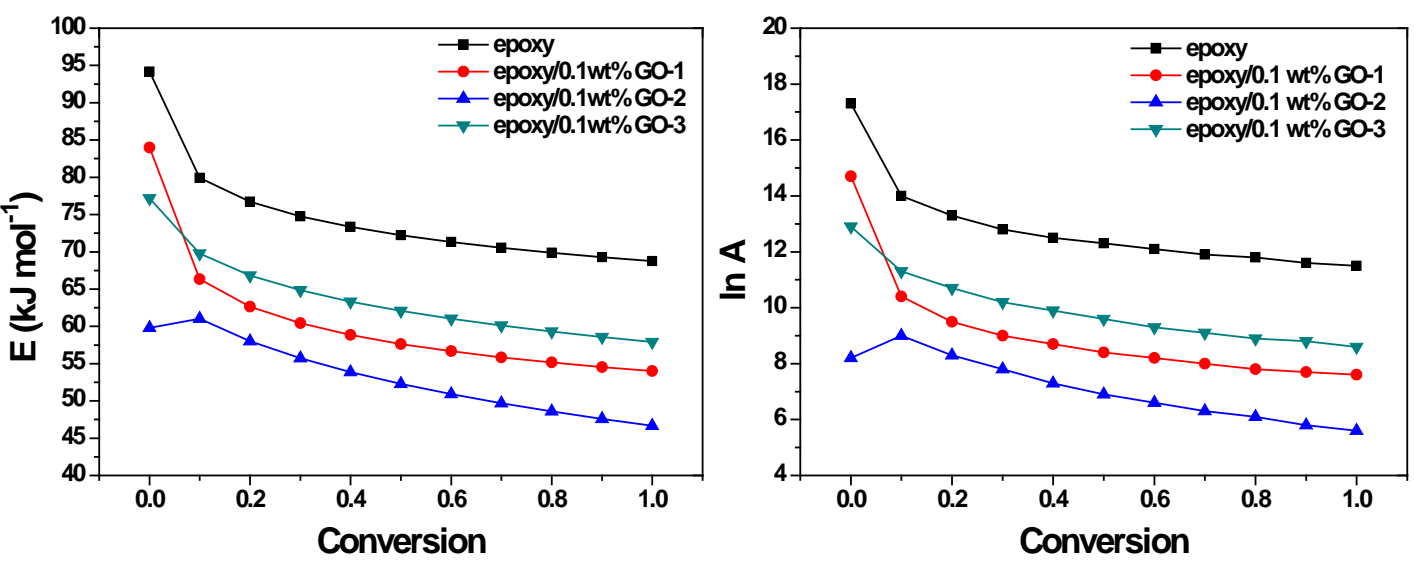

Figure 11. Activation energy and pre-exponential factor versus conversion for epoxy and its nanocomposites. 


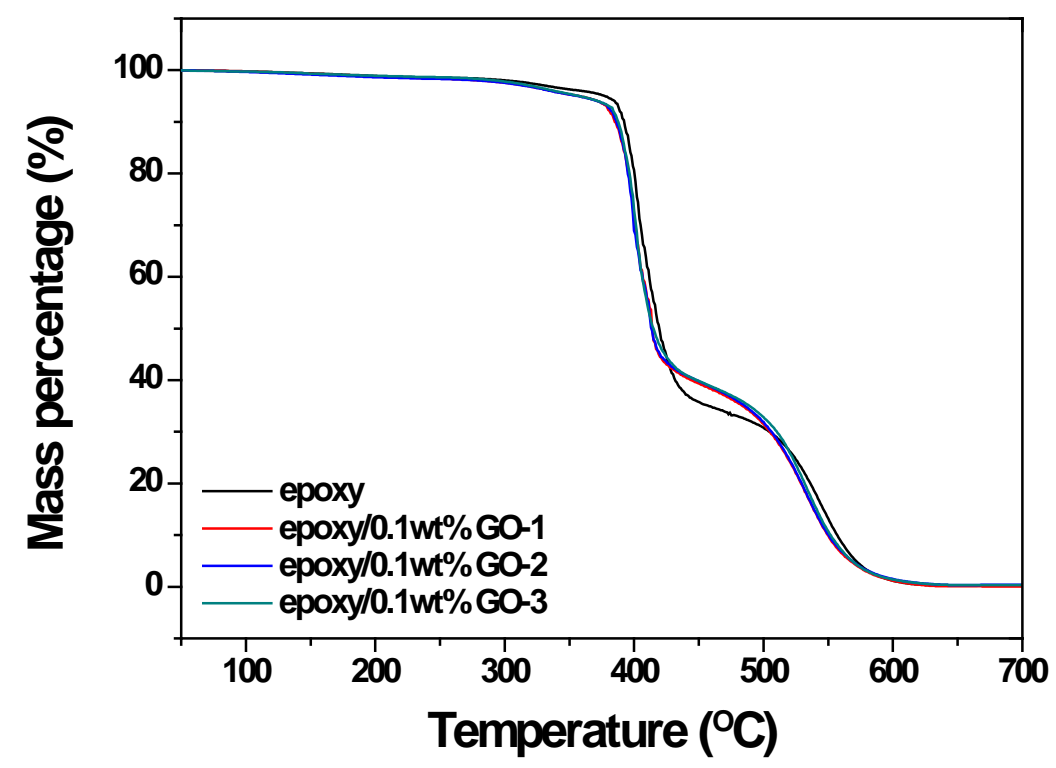

Figure 12. TGA plots of epoxy and its nanocomposites.

319 Table 4. Thermal properties of epoxy and its nanocomposites.

\begin{tabular}{llll}
\hline Sample & $I D T\left({ }^{\circ} \mathrm{C}\right)$ & $T_{\max }\left({ }^{\circ} \mathrm{C}\right)$ & Residue (\%) at $450^{\circ} \mathrm{C}$ \\
\hline Epoxy & 377 & 403 & 35.77 \\
GO-1/epoxy & 357 & 400 & 39.39 \\
GO-2/epoxy & 356 & 399 & 39.77 \\
GO-3/epoxy & 358 & 402 & 39.82 \\
\hline
\end{tabular}

321 The thermal stability of the cured epoxy resin and its nanocomposites with three sizes of

322 GO was evaluated by means of TGA. Figure 12 shows the TGA plots of the samples under air

323 atmosphere. Table 4 lists the main indicators including initial decomposition temperature

324 (IDT), temperature of the maximum rate of degradation $\left(T_{\max }\right)$ and residual weight percentage.

325 They were used to ascertain a materials lifetime. IDT corresponded to the temperature where

326 a 5\% mass loss was accumulated. $T_{\max }$ represented the stability at main mass loss stage. It was

327 determined at the peak of the differential Thermogravimetric curves. For the neat epoxy, it

328 exhibited an initial decomposition at $377^{\circ} \mathrm{C}$, where unreacted and labile epoxy chains or other 329 traces of impurities were broken [36]. The addition of GO, however reduced the IDT by about $33020^{\circ} \mathrm{C}$. It could result from the early decomposition of the interfacial epoxy chains, the cure of 
331 which was partially inhibited by the inclusion of the two dimensional graphene layers. At the 332 main stage of decomposition, sharp mass losses were observed in the epoxy and incorporated 333 systems, with $T_{\max }$ at about $400{ }^{\circ} \mathrm{C}$. The GO hardly affected the thermal behavior at this stage.

334 As the temperature was further increased, the samples experienced a steady mass loss stage in 335 the range of $420-500{ }^{\circ} \mathrm{C}$. The GO/epoxy nanocomposites showed higher thermal stability than 336 that of the pure epoxy resin at this stage. A $\sim 4 \%$ more residue was obtained in each 337 nanocomposite at $450^{\circ} \mathrm{C}$, compared with pure resin. The improved stability could be 338 attributed to the tortuous path effect of GO [31]. The presence of GO delayed the permeation 339 of oxygen and the escape of volatile degradation products as well as the formation of char. A 340 notable improvement can be achieved at very low loading of $0.1 \mathrm{wt} \%$, owing to the 341 tremendous surface area of GO. Moreover, the enhancement of the thermal properties was not 342 influenced by the variation of GO sheet size, but was determined by the loading of GO. The 343 three sizes of GO incorporated nanocomposites showed similar degradation behavior.

\section{Conclusions}

346 The incorporation of 0.1 wt\% GO catalyzed the curing reaction of epoxy resin. The activation 347 energy was reduced by $18.9 \%, 28.8 \%$ and $14.6 \%$ with addition of GO-1, GO-2 and GO-3, 348 respectively. GO-2 with medium size $(1.72 \mu \mathrm{m})$ showed the optimal catalytic effect on the 349 cure. It resulted from the minimal hindrance that confined the mobility of reactive groups.

350 The GO also improved the thermal stability of epoxy resin in the range of $420-500{ }^{\circ} \mathrm{C}$. A $\sim 4 \%$ 351 more residue was obtained in each of the incorporated system, compared with the pure resin.

352 However, the variations of GO sheet size did not influence the enhancement effect on the 353 thermal stability.

\section{Acknowledgments}

356 This work was funded by the National Natural Science Foundation of China (NSFC) (Grant 357 No. 51503205), Chinese Academy of Sciences (CAS) 'Light of West China’ Program. 
[1] Ratna D 2009 Handbook of thermoset resins (Shropshire: iSmithers)

[2] Barua S, Chattopadhyay P, Phukan M M, Konwar B K and Karak N 2014 Hyperbranched epoxy/MWCNT-CuO-nystatin nanocomposite as a high performance, biocompatible, antimicrobial material Mater. Res. Express 1045402

[3] Bedsole R W, Park C, Bogert P B and Tippur H V 2015 A critical evaluation of the enhancement of mechanical properties of epoxy modified using CNTs Mater. Res. Express

[4] Bindu Sharmila T K, Antony J V, Jayakrishnan M P, Sabura Beegum P M and Thachil E T 2016 Mechanical, thermal and dielectric properties of hybrid composites of epoxy and reduced graphene oxide/iron oxide Mater. Des. 90 66-75

[5] Liu S, Fan X and He C 2016 Improving the fracture toughness of epoxy with nanosilica-rubber core-shell nanoparticles Compos. Sci. Technol. 125 132-40

[6] Trihotri M, Dwivedi U K, Khan F H, Malik M M and Qureshi M S 2015 Effect of curing

[7] Wang X, Jin J and Song M 2012 Cyanate ester resin/graphene nanocomposite: curing dynamics and network formation Eur. Polym. J. 48 1034-41

[8] Hu J, Shan J, Zhao J and Tong Z 2015 Water resistance and curing kinetics of epoxy resins with a novel curing agent of biphenyl-containing amine synthesized by one-pot method

[9] Wan J, Gan B, Li C, Molina-Aldareguia J, Kalali E N, Wang X and Wang D-Y 2016 A

[10] Sánchez-Cabezudo M, Prolongo M G, Salom C and Masegosa R M 2006 Cure kinetics of epoxy resin and thermoplastic polymer J. Therm. Anal. Calorim. 86 699-705 
DGEBA-DDS epoxy using ultrasonic, dynamic mechanical, and thermal probes Polym.

[12] Zhang Z, Liang G, Ren P and Wang J 2008 Curing behavior of epoxy / POSS / DDS hybrid systems Polym. Compos. 51 1-7

[13] Arabli V and Aghili A 2013 Effect of silica nanoparticles on the curing kinetics of epoxy vinyl ester resin Proc. Int. Conf. Nanomater. Appl. Prop. 2 03NCNN26

[14] Ferdosian F, Ebrahimi M and Jannesari A 2013 Curing kinetics of solid epoxy/DDM/nanoclay: Isoconversional models versus fitting model Thermochim. Acta

[15] Zhou T, Wang X, Liu X and Xiong D 2009 Influence of multi-walled carbon nanotubes on

[16] Zheng X, Li D, Feng C and Chen X 2015 Thermal properties and non-isothermal curing kinetics of carbon nanotubes/ionic liquid/epoxy resin systems Thermochim. Acta 618 1825

[18] Zhou T, Wang X and Wang T 2009 Cure reaction of multi-walled carbon

[17] Zhou T, Wang X, Liu X H and Lai J Z 2010 Effect of silane treatment of

[19] Li A, Li W, Ling Y, Gan W, Brady M A and Wang C 2016 Effects of silica-coated carbon

[20] Xie H, Liu B, Sun Q, Yuan Z, Shen J and Cheng R 2005 Cure kinetic study of carbon nanofibers/epoxy composites by isothermal DSC J. Appl. Polym. Sci. 96 329-35

[21] Vertuccio L, Russo S, Raimondo M, Lafdi K and Guadagno L 2015 Influence of carbon nanofillers on the curing kinetics of epoxy-amine resin RSC Adv. 5 90437-50 
[22] Abdalla M, Dean D, Robinson P and Nyairo E 2008 Cure behavior of epoxy/MWCNT nanocomposites: The effect of nanotube surface modification Polymer 49 3310-7

[23] Jana S and Zhong W-H (Katie) 2009 Curing characteristics of an epoxy resin in the presence of ball-milled graphite particles J. Mater. Sci. 44 1987-97

[24] Guo B, Wan J, Lei Y and Jia D 2009 Curing behaviour of epoxy resin/graphite composites containing ionic liquid J. Phys. D Appl. Phys. 42145307

[25] Wang X, Jin J and Song M 2013 An investigation of the mechanism of graphene toughening epoxy Carbon 65 324-33

[26] Wang X and Song M 2013 Toughening of polymers by graphene Nanomater. Energy 2 137

[27] Wang F, Drzal L T, Qin Y and Huang Z 2016 Size effect of graphene nanoplatelets on the morphology and mechanical behavior of glass fiber/epoxy composites J. Mater. Sci. 51

[28] Qiu S L, Wang C S, Wang Y T, Liu C G, Chen X Y, Xie H F, Huang Y A and Cheng R S 2011 Effects of graphene oxides on the cure behaviors of a tetrafunctional epoxy resin Express Polym. Lett. 5 809-18

[30] Li L, Zeng Z, Zou H and Liang M 2015 Curing characteristics of an epoxy resin in the presence of functional graphite oxide with amine-rich surface Thermochim. Acta 614 76-

[31] Wang X, Xing W, Zhang P, Song L, Yang H and Hu Y 2012 Covalent functionalization of graphene with organosilane and its use as a reinforcement in epoxy composites Compos. Sci. Technol. 72 737-43

[32] Wan Y J, Yang W H, Yu S H, Sun R, Wong C P and Liao W H 2016 Covalent polymer functionalization of graphene for improved dielectric properties and thermal stability of epoxy composites Compos. Sci. Technol. 122 27-35 
442 [33] Liu S, Yan H, Fang Z and Wang H 2014 Effect of graphene nanosheets on morphology, 443 thermal stability and flame retardancy of epoxy resin Compos. Sci. Technol. 90 40-7

444 [34] Hummers W S and Offeman R E 1958 Preparation of graphitic oxide J. Am. Chem. Soc. 445 80(6) 1339

446 [35] Kamal M R 1974 Thermoset characterization for moldability analysis Polym. Eng. Sci. 14 447 231-9

448 [36] Thomas R, Yumei D, Yuelong H, Le Y, Moldenaers P, Weimin Y, Czigany T and Thomas 449 S 2008 Miscibility, morphology, thermal, and mechanical properties of a DGEBA based 450 epoxy resin toughened with a liquid rubber Polymer 49 278-94

451 